\title{
Utilisation of e-collaboration tools for effective decision-making: A developing country public-sector perspective
}

Authors:
Samuel Akinsola ${ }^{1}$ (1)
Judith Munepapa ${ }^{1}$ (1)
Affiliations:
${ }^{1}$ Department of Informatics,
Faculty of Computing and
Informatics, Namibia
University of Science and
Technology, Windhoek,
Namibia
Corresponding author:
Samuel Akinsola,
sakinsolas@gmail.com
Dates:
Received: 09 Apr. 2019
Accepted: 19 Nov. 2019
Published: 04 Mar. 2021
to read online.
How to cite this article:
Akinsola, S. \& Munepapa, J.,
2021, 'Utilisation of
e-collaboration tools for
effective decision-making:
A developing country
public-sector perspective',
South African Journal of
Information Management
23(1), a1099. https://doi.org/
10.4102/sajim.v23i1.1099
Copyright:
(c) 2021. The Authors.
Licensee: AOSIS. This work
is licensed under the
Creative Commons
Attribution License.

Background: Collaboration is about coming together of two or more individuals or entities to combine either tangible or non-tangible resources in achieving a set goal or objective, regardless of distance, time and location; an outcome that may otherwise have been difficult to accomplish independently. However, utilisation of e-collaboration resources for exchange of knowledge is yet to be adopted by developing country public organisations for effective decision making.

Objectives: The objective of this study was to assess and determine the extent to which publicsector managers currently use e-collaboration resources to support their decision-making processes, and examine challenges hampering e-collaboration.

Method: A qualitative approach was followed using a case study design on a public organisation in Namibia. The selected case has departments, directorates and divisions and offices across Namibia. Case study data collection instruments were utilised. A judgemental sampling technique was used for the selection of 120 participants.

Results: There is somewhat usage of e-collaboration resources in public organisations; however, lack of enabling competencies to use available e-collaboration functionality; most public-sector managers continue to depend on the traditional callaborative approaches.

Conclusion: E-collaboration resources have become an integral part of facilitating decisionmaking in organisations, including the public sector; because information or knowledge sharing is essential for effective decision-making. Collaboration among stakeholders can have great influence on managers and foster change in the processes and approaches currently being utilised. This study contributes to the collaboration of resources for improving the managers' decision-making in public organisations.

Keywords: e-collaboration tools; ICT; collaboration; public sector; decision-making.

\section{Introduction}

Despite its several benefits and the ease at which fragmented and heterogeneous sources of information could be integrated, analysed and harnessed for effective decision-making, the public sector of several countries, including Namibia, is generally slow in adopting technology. The reliance on brick-andmortar access to relevant information has remained a challenge for the speedy and timely service delivery. The process of sourcing appropriate information to make a decision in the public sector is cumbersome; in addition, adhering to governing acts and policies require varied checks and approval is required from numerous levels of managers. This internal governmental information drives the legitimacy, credibility, transparency and responsiveness of government to societal needs.

Decision-makers are expected to have a better understanding of their operational context and its interconnection with other departments or functional units of other public services (SzymaniecMlicka 2017), thus determining what may be required for the exchange of views with varied stakeholders on pertinent societal challenges both within and outside the establishment. There is a need for shared knowledge and understanding with different stakeholders who are most often not restricted by location, but are highly mobile and in geographically dispersed locations (Varty, O’Neill \& Hambley 2017).

A report carried out by the Namibia Ministry of Information and Communication Technology (ICT) in 2009 indicates that the adoption and usage of ICT in the Namibian public sector is fast 
growing, thereby providing new opportunities and approaches of interest in increasing the rate of development in the country. Previously, the Namibian government had introduced into the public sector several key enablers for the achievement of its development objectives, which are outlined in the Fifth National Development Plan (NDP5) tagged 'Vision 2030', the Harambee Prosperity Plan (HPP) and the e-Government initiatives. Hence, Namibian public sector needs to digitally transform and increase its efforts on moving with technological adoption, and usage in its operations as being commonly witnessed around the world is a necessity (Lönn 2016).

\section{Public-sector usage of e-collaboration}

Decision-makers are expected to have better understanding of their operational context and linkage with other departments or functional units of other public institutions, thereby enabling them to provide more comprehensive delivery of services to the public. Service delivery requires exchange of views from varied stakeholders on pertinent societal challenges both within and outside the establishment. The need for shared knowledge and understanding from different stakeholders who are most often not restricted by location but are highly mobile and in geographical dispersed locations makes e-collaboration a necessity (Beranek 2006). Collaboration in the context of this study is an interactive process that enables the engagement of two or more individuals to work together in achieving an outcome which they may not otherwise accomplish independently (Lock \& Redmond 2009; Salmons \& Wilson 2009). In other words, when collaboration takes place through the use of Internet technologies, it is considered as e-collaboration. E-collaboration, therefore, is the use of Internet resources by two or more individuals, known as collaborators, for the facilitation of exchange of information, ideas and documents. The advancement in ICT has further increased the number of collaboration tools available other than telephone, but including Internet technologies such as email, instant messaging, video conferencing and the likes. Individuals can work together and reflect on their views to make effective decisions (Nikoi \& Boateng 2013). The demand and the need to provide timely access to qualitative governmental information necessitate that every stakeholder's opinion should be considered before making decisions. To make information available to the public makes the bricks-and-mortar collaboration inefficient, and hence the need for the usage of ICTs enabled technologies for collaboration.

Namibia has some apparent organisational challenges that can hinder the application of Internet-based collaboration tools in the public sector (Wahl \& Kitchel 2016). For example, information systems and other ICT technological applications such as Skype for Business and Microsoft SharePoint were introduced as innovation to encourage online collaboration, but they are currently not being used; traditional collaboration approaches persist, while decision-making processes remain unchanged. Even though the usage of ICTs enabled technologies for collaboration with diverse stakeholders, including service providers and subject specialists - be it within the organisation, external, service recipients or for exchanging ideas, skills, expertise, and to share information for effective decision-making - adoption and utilisation have remained unofficial (Scott \& Thomas 2016).

The use of e-collaboration, specifically in the Namibian public-sector organisations, needs a shift from the current traditional approaches, where face-to-face meetings, telephone, faxes and, relatively, emails have remained the norms of engagement with stakeholders, if decision-making processes requiring various sources of input are to be expedited for effective service delivery. In addition, these traditional collaboration approaches are inefficient in terms of cost and risk of assembling stakeholders, and inadequate especially in this age of digital transformation where demand for promptly delivered services is increasing. Thus, there is a need to take full advantage of the opportunities that utilisation of e-collaboration is provided for Namibian public organisations by encouraging new work ethics to support decision-making in the public sector (Kauffman \& Carmi 2017). Therefore, this article aims at encouraging public-sector managers' orientation towards adopting and adapting the most appropriate e-collaboration tools that can assist in facilitating effective decision-making.

\section{Conceptual framework}

Advances in computing and communication technologies have allowed businesses and organisations to become more distributed and dynamic in nature. This spread and dynamism have divided important organisational entities, such as tasks, contexts, knowledge, specialisation and, more importantly, humans, based on a variety of factors such as time, geography, structure and roles (Kim et al. 2004). In order to take advantage of the advances and potential of ICTs as demand for improved services delivery increases, decision-makers in public organisations require reorientation for timely utilisation of ICT resources that will enable them to make effective decisions which are aligned with the demand of their services.

\section{E-collaboration tools improve decision-making}

Naik (2015) argued that business decisions requiring collaboration cannot be made in isolation. The decisionmaking process in any organisation most often will have to involve different stakeholders, thereby necessitating the use of collaborative tools. These tools will not only make collaboration and decision-making simpler and faster, but also effective and efficient. According to Mauher (2011), decision-making process aims at generating conclusions that need varying contributions and perceptions. Also, it generates the documents specifying what, who, when, why and how someone acts to achieve given conclusions or requirements. These generated requirements are directed to achieve specified strategic organisational outcomes, which are based on a given specification and planned scenario of activities, schedules and workflows. The decision-making process 
involves the existence of a problem that must be understood by the decision-maker and accurately defined to find opportunities for its solution (Negulescu 2014).

Figure 1 shows a summarised decision-making process as presented by Negulescu (2014).

Bettoni et al. (2016) asserted that collaborative efforts of employees within the organisation and those of external stakeholders are both needed for effective decision-making. The advent and subsequent improvement in information and communication systems as indicated by Wohlrab et al. (2018) has impacted positively collaborative efforts of organisations and made the implementation of e-collaboration easier.

According to Anders (2016) and Markovski, Koceska and Koceski (2013), ICTs have created an environment where teams can communicate and exchange views across time and space. Team members need to possess knowledge and skills that can help them communicate and collaborate to accomplish tasks. Wohlrab et al. (2018) opined that communication and collaboration can lead to better results, meaning that there will be a reduction in costs, and conflicts will be prevented and solved between participants. Therefore, technologies such as e-collaboration are made available as they create platforms that allow the exchange of information, ideas and documents. Individuals are empowered to work together, share experiences and intuitions, and reflect on their views before making decisions (Nikoi \& Boateng 2013). Lee (2007) also asserted that synchronous distributed interaction requires enriching support for communication because group members in distant locations may lose much information or awareness, such as who is talking or what others are doing, while asynchronous interaction needs substantial support in the coordination of activities, such as when each group member is supposed to accomplish a task. Synchronous interaction in same place gains numerous benefits from collaboration technologies, emphasising cooperation which enhances information sharing and manipulations of shared documents.

\section{E-collaboration tools support information flow}

According to De Vreede et al. (2016) and Hastings (2009), technology-mediated collaboration can fall into four categories: (1) same time, same place (phone conference within the same building); (2) same time, different place (phone conference or web meeting within the same organisation between two members in different buildings); (3) different time, same place

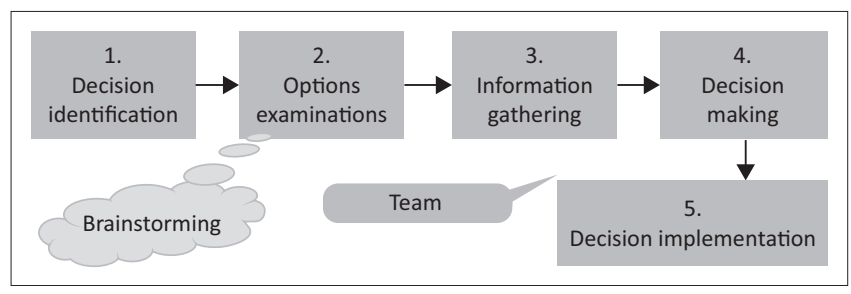

Source: Negulescu, O.H., 2014, 'Using a decision-making process model in strategic management', Review of General Management 19(1). viewed 06 March 2018 from, https:// www.managementgeneral.ro/pdf/1_2014_10.pdf

FIGURE 1: Decision-making process. (shared files on a network); or (4) different time, different place (email and voice mail exchanges).

Sundaravej (2013) affirmed that synchronous collaboration technologies allow all participants from the same or different locations, time zones or organisations to collaborate on the same task in real time, while asynchronous collaboration is used when participants wish to share information, but simultaneous interaction is not necessary.

According to Varty et al. (2017) and Fedorowicz et al. (2008), e-collaboration technologies can supply seamless connectivity to allow work anywhere and anytime. Moreover, they can help to manage the complexity derived from the diversity of workers, knowledge and other resources that must coordinate efforts on a collective creative task. E-collaboration technologies can ensure access to contextualise services that will assure easy interaction amongst team members.

\section{Methodology}

A qualitative approach was followed using a case study design on a public organisation in Namibia. The selected public organisation has departments, directorates and divisions. It has offices spread all across Namibia. Data were collected using interviews, observations and questionnaires. Semi-structured interviews were conducted based on a loose structure consisting of open-ended questions that define the area to be explored, at least initially, and from which the interviewer or interviewee may diverge to pursue an idea in more detail (Brinkmann 2014). The population of the study comprises 1600 staff of a Namibia public organisation utilised as the context for this study. A judgemental sampling technique was used to select 120 participants, which included 50 participants from the directorate, 40 participants from the department and 30 participants from the division in the organisation. The reason for using a judgemental sampling technique is for a better identification of respondents who has knowledge of the study in question. In the study, only 45 out of the 120 were eventually interviewed, as no new knowledge or value thereafter added to already collected information from the participants.

The observation method was used to observe the working culture of members of staff based on their daily activities in order to have a better understanding of their work behaviour.

Data were analysed based on the following areas of interest of the participants (see Figure 2):

- roles and responsibilities

- need for collaboration

- organisation and department

- channels of communication

- strategies for collaboration.

\section{Results and discussion}

It was revealed that each of the participants was aware of what is expected of them as they clearly defined their roles and responsibilities. The roles and responsibilities are hierarchical 
in nature; decisions taken were based on a bottom-up approach in accordance to allocated tasks and functions. There were no units or sections that function in isolation as most of the roles and responsibilities of the participants are highly dependent on the involvement of other departments, directorates or divisions to make final decisions. This perception was corroborated when one of the participants said:

'My role is to facilitate private investments in public infrastructure investments; facilitating in writing legislations and policies that clarify this area, we do a lot of capacity building, but most importantly we work with other government ministries in helping them bring their infrastructure development on public service delivery projects that they want to get done with private participation from a conception stage to the level of maturity.' (Top management and decision maker)

A participant from the Information Technology division said that his role in the division was to meet the service requirements of all other departments, directorates and divisions, while another participant from the training division emphasised that her role was to provide training to the employees from all the departments, directorates and divisions. Thus, any decision-making on service requirements or training, at either the Information Technology division or the training division, will depend on the outcome communicated from respective departments, directorates and divisions. In public organisation, according to Bolfíková, Hrehová and Frenová (2010), decisionmakers (managers) must have the authority, information or resources desirable for decision-making. Otherwise, lack of experiences, relevant information accessible to decisionmakers, will often lead to failure when implementing policies in public organisations. Overcoming this challenge will require that many of the decision-makers collaborate more with experienced, knowledgeable and well-skilled stakeholders for

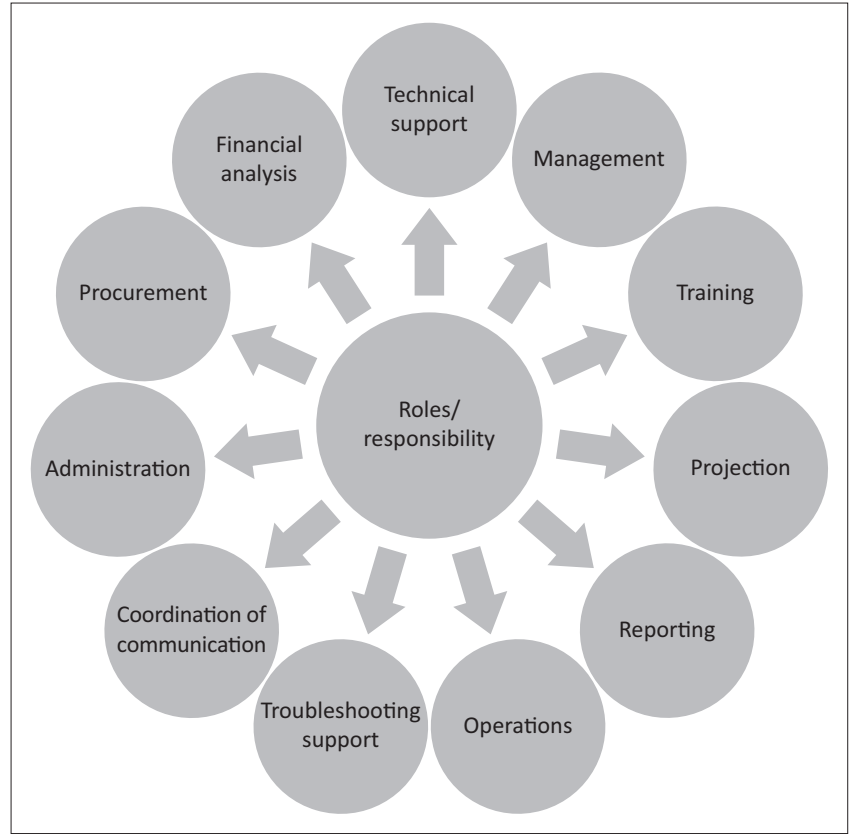

Source: Munepapa, J., 2018, 'E-collaboration framework for effective decision-making in the Namibian public organization', Master's thesis, Namibia University of Science and Technology, Windhoek

FIGURE: 2 Roles and responsibilities of participants. better decision-making. In addition, as indicated by Zaraté, Konate and Camilleri (2013), decision-making efficiency depends on managers' capability to deal with issues concerning planning, leading, organising and controlling the activities within their organisation. Managers need to lead with a purpose, focusing on their own and others' efforts on the overall shared mission, vision, objectives and goals in line with their strategies and values.

Collaboration is a necessity in public organisations as they strive to meet the need of stakeholders, consisting of people and the various segments of communities in the country. As shown in Figure 3, there are various reasons and needs requiring collaboration. Based on the findings, collaboration at the workplace takes different forms; to select suitable and appropriate collaboration tools, decision-makers seeking information are expected to take into consideration the context, needs and stakeholders involved. Respondents had a different opinion regarding the reasons for collaborating with other departments, directorates and divisions.

\section{One of the participants asserted that:}

'Basically if there is a new project that has to be brought up, the business comes with what they want we look for solutions, and present it to them and according to that we make a collaborative decision on the way forward to attain the objectives that the business is trying to achieve.' (Top management and decision maker)

However, another participant felt that they only work with other departments or external stakeholders whenever they have a need to share information. Moreover, a participant in the Information Technology division believed that they need to collaborate with departments to enable support for department business needs and service requirements, for

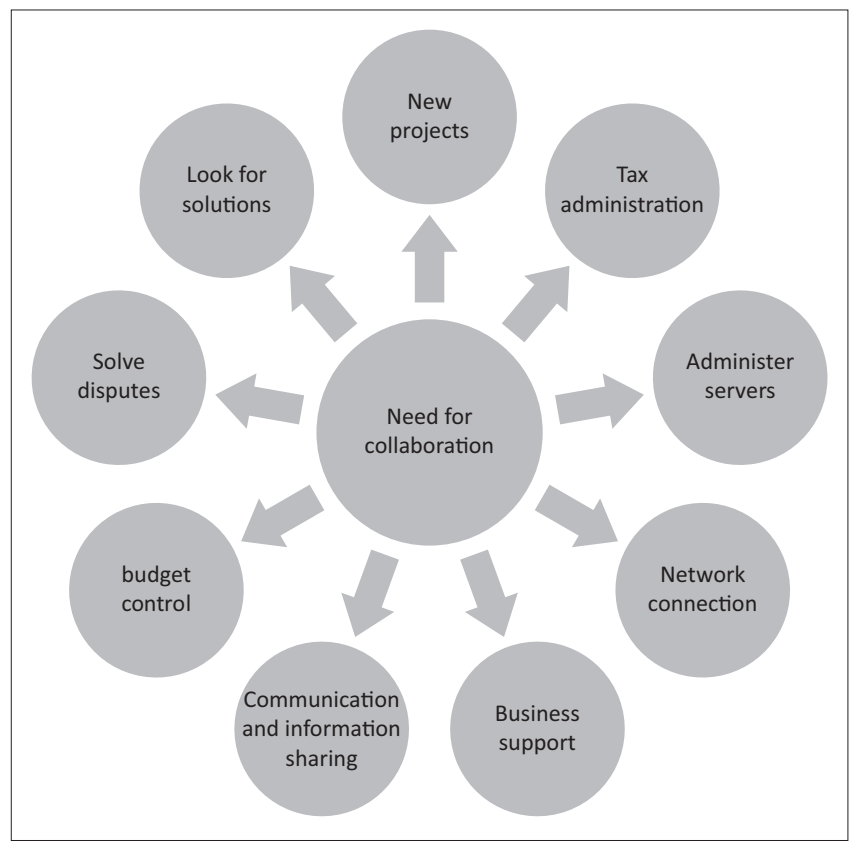

Source: Munepapa, J., 2018, 'E-collaboration framework for effective decision-making in the Namibian public organization', Master's thesis, Namibia University of Science and Technology, Windhoek

FIGURE 3: Context and need for collaboration within the organisation. 
example, when there is a need for departments to purchase computer hardware, software and other peripherals, including installation and maintenance.

Another participant expressed that they worked with all Organisations, Ministry's or Agencies for budget allocation and control because the Ministry of Finance is focal of finances in the public sector. Participants within the Department of Inland Revenue (IRD) expressed that they worked with many external stakeholders for all the tax administration and collection. Several participants alluded to the fact that most public organisations consist of highly dispersed departments for the purpose of getting closer to the people; this has enabled them to be located within all corners of the country. In addition, employee transfers, relocation and reorganisation are common occurrences in public organisations, thereby encouraging information sharing and stressing the importance of collaboration in public organisation, and the significant of e-collaboration when making a decision. Collaboration can re-invigorate organisations by fully engaging employees, improving retention, breaking down silos and fostering cross-functional activities to encourage better innovation.

Most of the participants expressed the fact that they applied different tools depending on the prevailing challenges, context or situations when managing their various interactions with stakeholders. Collaboration is all about working together to accomplish a common goal. The respondents explained that collaboration is needed when a new project emerges, particularly when there are several stakeholders involved. These stakeholders interact at different levels of coordination and communication is essential for the success of each project embarked upon. Knowledge of an individual is increased when people with varied experiences share their understanding and know-how. Hence, it is the responsibility of managers to seek input from these stakeholders that will contribute different expertise, skills and knowledge. These stakeholders might be distributed across different locations and time zones; therefore, the use of collaborative tools would enable managers to elicit ideas that will help prevent any sort of poor performance of the project.

In a public organisation, there are varied stakeholders and interest groups to collaborate with, including nongovernmental organisations, private business, and the general public, as elucidated by the participants and shown in Figure 4; therefore, it is essential to know the effect of government policies and their implication as perceived from different stakeholders within and from other external organisations (Figure 5).

In this study, most of the participants identified (1) email, (2) telephone, (3) internal memos/letters and (4) face-to-face meetings as the preferred channels of communication whenever the need to collaborate arises. All the respondents opined the use of email as the easiest and most convenient method. It is common believe among participants that telephone, either fixed or mobile, enables collaborative task initiators to send an alert or a follow-up as a form of a reminder with the recipient of email, whose response is been anticipated. However, a face-to-face meeting is regarded as one of the most used channels to solicit information and idea to enhance decision-making. Majority of the participants were of the view that a meeting is appropriate because in a meeting everyone comes together despite its cost implication to give their input on a matter that needs to be attended. The

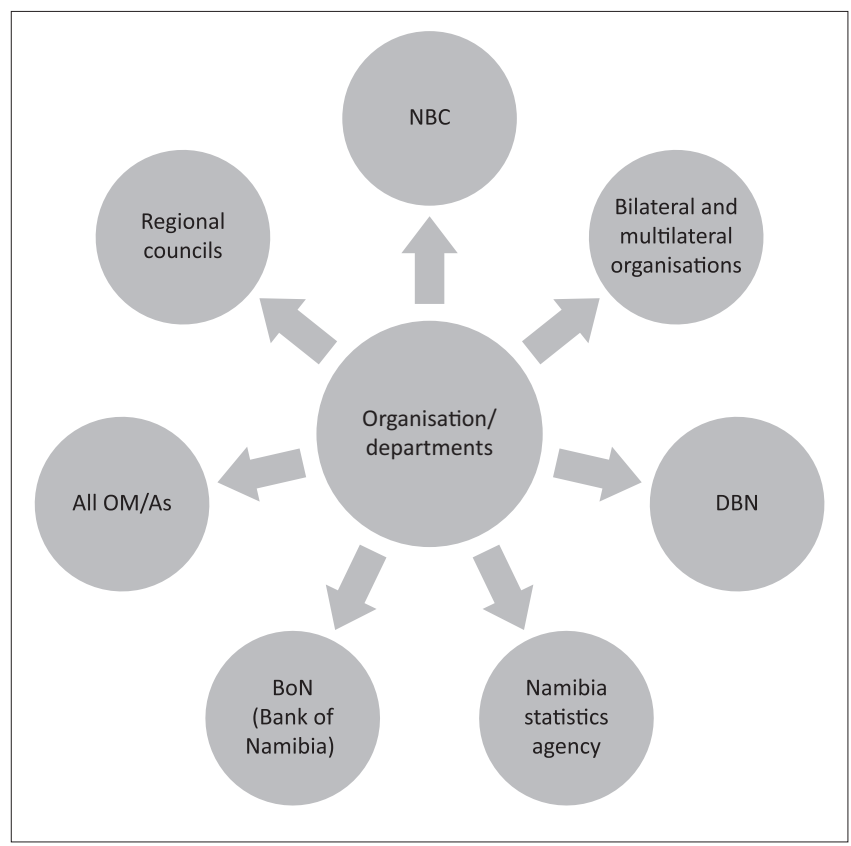

Source: Munepapa, J., 2018, 'E-collaboration framework for effective decision-making in the Namibian public organization', Master's thesis, Namibia University of Science and Technology, Windhoek

FIGURE 4: Department and other external organisations with which collaboration take place.

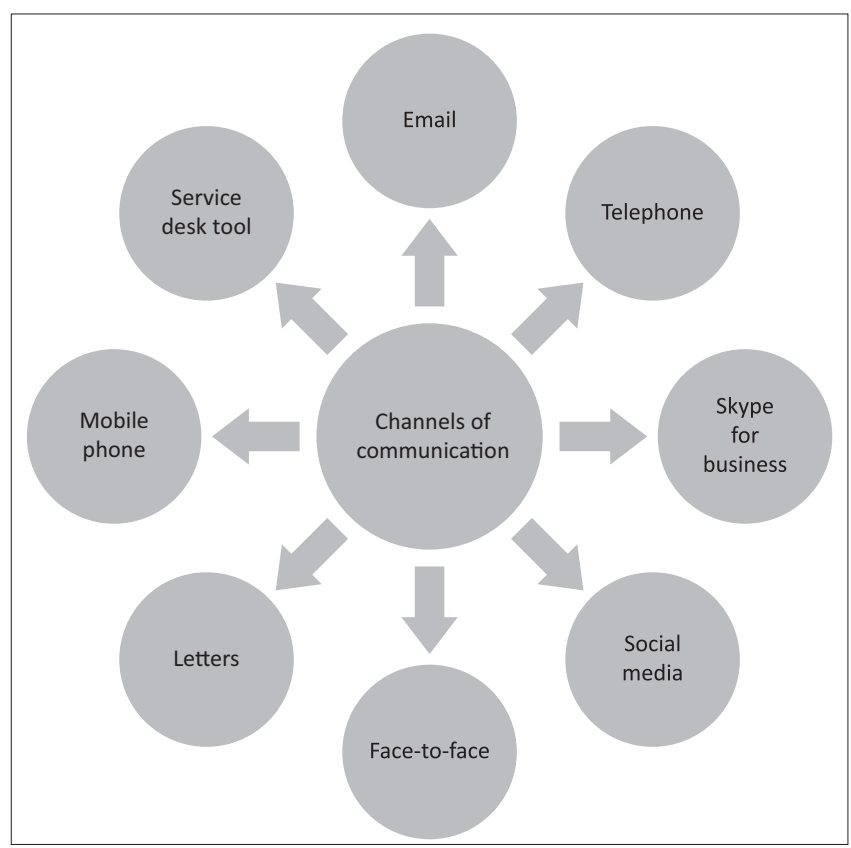

Source: Munepapa, J., 2018, 'E-collaboration framework for effective decision-making in the Namibian public organization', Master's thesis, Namibia University of Science and Technology, Windhoek

FIGURE 5: Communication channels utilised for collaborations in Namibia context. 
respondents believed this could be the most effective channel if a group of experienced and skilled individuals are involved. Skype for business and service desk tools were considered as relevant, but are rarely or least used tools for the purpose of collaboration (Figure 6).

The respondents did not seem to have strategies except shifting between the channels of communication available to them. However, the respondents mentioned that they would like to see to combat the current challenges. The respondents felt that they would like to see new software introduced that will support their information sharing, tools that will allow open communication and build brainstorm, and platforms that will allow them to give suggestions and contribute to pending decision-making.

\section{Conclusion}

The findings of this study revealed that the Namibian public sector still has major challenges when it comes to the utilisation of ICT, especially in the area of e-collaboration tools. Areas like technical support, coordination of communication, training and reporting are very important and must be investigated. The respondents interviewed stated that the public sector should put more effort into the area of collaboration as this will bring about effective networking and contribution from individuals with an adequate understanding of the subject under focus in the public sector. The respondents also noted that proper communication channels should be utilised to allow for a free flow of information. Finally, the need for strategic plans was pointed out by the respondents as this will give the public sector a good perspective of how to go about adopting collaboration tools in the public service. Furthermore, more efforts are needed from the managers to incorporate

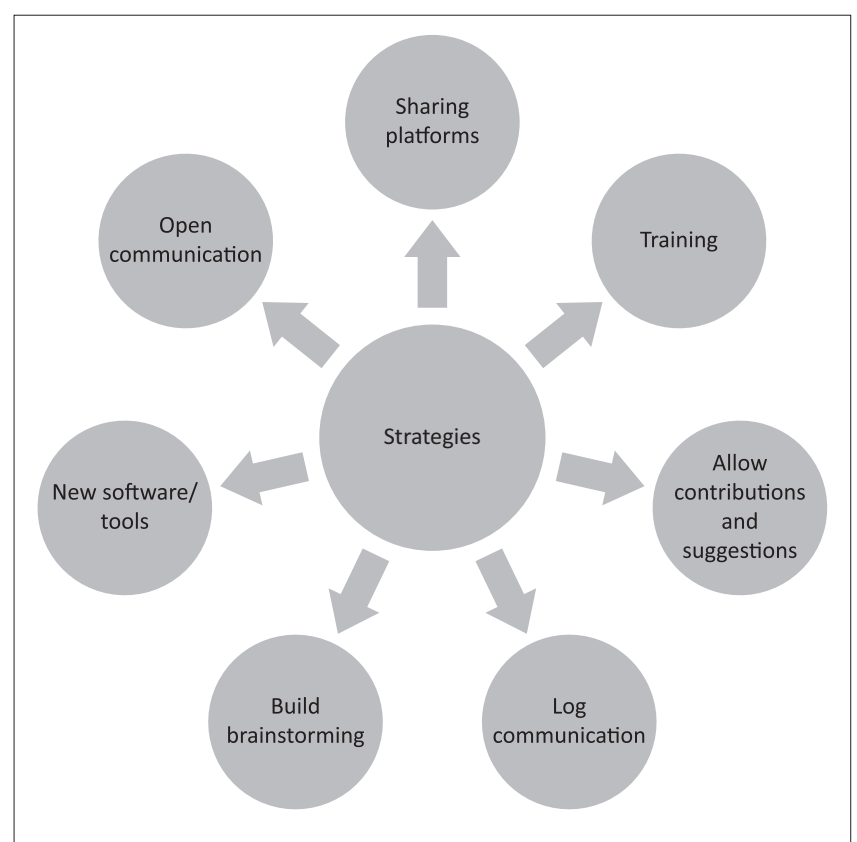

Source: Munepapa, J., 2018, 'E-collaboration framework for effective decision-making in the Namibian public organization', Master's thesis, Namibia University of Science and Technology, Windhoek

FIGURE 6: Strategies for overcoming challenges of collaboration in public organisation. these innovative ideas to have effective decision-making. The results showed that there is a range of collaboration tools that respondents were conversant with across departments, directorates and divisions. Different collaboration tools have their strengths and weaknesses, and were used for different purposes. The findings showed that the use of email was the primary mode of communication within the departments, directorates and divisions.

\section{Recommendations}

E-collaboration tools have become an important part of facilitating decision-making in organisations, including the public sector. If decision-makers wish to form relationships, they need to build and develop a platform of trust. Information and knowledge sharing is essential in the public sector, as it plays a vital role in effective decision-making, and communication becomes open and transparent. Collaboration efforts within an organisation could be influenced by the managers and their willingness to change the process and approaches being used for collaborative activities to take place.

Moreover, decision-making depends on the resources available - such as skills and knowledge - and not necessarily on the tools for making a decision alone. Thus, the mindset of managers and employees needs to be change to creative ideas that can incorporate the use of new tools. This study offered the opportunity for this area of research to be explored to another level, particularly in the public-sector organisations.

\section{Acknowledgements}

The authors would like to thank Namibia University of Science and Technology, Windhoek, Namibia for the resource provision and support to conduct this study.

\section{Competing interests}

The authors have declared that no direct or indirect interests exist with regard to the writing of this article.

\section{Authors' contributions}

The study was conducted by J.M. and supervised by S.A.

\section{Ethical consideration}

In this article, the researchers adhered to and followed all ethical standards for research.

\section{Funding information}

Funding of resources and support for the study were provided by institutional postgraduate research of the Namibia University of Science and Technology.

\section{Data availability}

Data sharing is not applicable to this article due to confidentiality agreement with the case under study. 


\section{Disclaimer}

The views and opinions expressed in this article are those of the authors and not an official position of the Namibia University of Science and Technology, Windhoek, Namibia.

\section{References}

Anders, A., 2016, 'Team communication platforms and emergent social collaboration practices', International Journal of Business Communication 53(2), 224-261. https://doi.org//10.1177/2329488415627273

Beranek, T.R., 2006, 'Global project management: Graduate course', M.S. dissertation, Publication No. AAT 1436365, University of Maryland, College Park, MD.

Bettoni, M.C., Bittel, N., Bernhard, W. \& Mirata, V., 2016, eSF: An e-collaboration system for knowledge workers, IGI Global, Hershey, PA.

Bolfíková, E., Hrehová, D. \& Frenová, J., 2010, 'Manager's decision-making in organizations: Empirical analysis of bureaucratic vs. learning approach', Zbornik Radova Ekonomskog Fakulteta u Rijeci: Časopis za Ekonomsku Teoriju i Praksu 28(1), 135-163. https://doi.org/65.012.4:005.731

Brinkmann, S., 2014, 'Interview', in T. Teo (ed.), Encyclopedia of critical psychology, pp. 1008-1010. Springer, New York. https://doi.org/10.1007/978-1-4614-5583pp. 1008

De Vreede, G., Antunes, P., Vassileva, J., Gerosa, M.A. \& Wu, K., 2016, 'Collaboration technology in teams and organizations: Introduction to the special issue', Information Systems Frontiers 18(1), 1-6. https://doi.org/10.1007/s10796-016-9632-3

Fedorowicz, J., Laso-Ballesteros, I. \& Padilla-Meléndez, A., 2008, ‘Creativity, innovation, and c-collaboration', International Journal of E-Collaboration 4(4) 1-10. https://doi.org/10.4018/jec.2008100101

Hastings, R., 2009, Collaboration 2.0, viewed 12 April 2018, from https://www. techsource.ala.org.

Kauffman, G. \& Carmi, G., 2017, 'E-collaboration of virtual teams: The mediating effect of interpersonal trust', ICEBI 17: 2017 International Conference on E-Business and Internet Taichung Taiwan, Association for Computing Machinery, New York, May 27, 2017, pp. 45-49. https://doi.org/10.1145/3092027.3092039

Kim, S., Godbole, A., Huang, R. \& Smari, W., 2004, 'Toward an integrated humancentered knowledge-based collaborative decision making system', Proceedings of the 2004 IEEE International Conference on Information Reuse and Integration, Dayton University, OH, November 8-10, 2004, viewed 22 February, 2018, from https://doi.org/10.1109/IRI.2004.1431493

Lee, C., 2007, 'Boundary negotiating artifacts: Unbinding the routine of boundary objects and embracing Chaos in collaborative work', Computer Supported Cooperative Work 16,307-339, viewed 10 April 2017, from https://depts. washington.edu/csclab/wordpress/wp-content/uploads/Lee-2007.pdf.
Lock, J.V. \& Redmond, P., 2009, 'Working collaboratively on the digital global frontier', in J. Salmons \& L. Wilson (eds.), Handbook of research on electronic collaboration and organizational synergy, pp. 177-191, IGI Global, Hershey, PA. https://doi. and organizational synergy, pp. 177-191,
org/10.4018/978-1-60566-106-3.ch012

Lönn, C., 2016, 'E-Government collaboration in the Swedish public sector: Multiple studies on collaboration facilitators and collaboration modes', PhD dissertation, Dept. of Computer and Systems Sciences, Stockholm University, Stockholm.

Markovski, G., Koceska, N. \& Koceski, S., 2013, 'Improving enterprise efficiency using IT collaboration systems', Journal of Applied Economics and Business 1(4), 95-103.

Mauher, M., 2011, 'Managing goal focused e-collaboration in regional government', in Proceedings of the 34th international convention, MIPRO, IEEE, Croatia May 23Proceedings of the 34th inte
27,2011 , pp. 1597-1602.

Munepapa, J., 2018, 'E-collaboration framework for effective decision-making in the Namibian public organization', Master's thesis, Namibia University of Science and Technology, Windhoek.

Naik, D., 2015, 'Organizational use of social media: The shift in communication collaboration, and decision-making', Masters' dissertation, viewed 15 August 2018, fromhttp://citeseerx.ist.psu.edu/viewdoc/download?doi=10.1.1.1004.6982

Negulescu, O.H., 2014, 'Using a decision-making process model in strategic management', Review of General Management 19(1). viewed 06 March 2018 from, https://www.managementgeneral.ro/pdf/1_2014_10.pdf

Nikoi, E. \& Boateng, K., 2013, Collaborative communication processes and decision making in organizations, IGI Global, Hershey, PA.

Salmons, J. \& Wilson, L., 2009, Handbook of research on electronic collaboration and organizational synergy, IGI Global, Hershey, PA, New York.

Scott, T.A. \& Thomas, C.W., 2016, 'Unpacking the collaborative toolbox: Why and when do public managers choose collaborative governance strategies?', Policy Studies Journal 45(1), 191-214. https://doi.org/10.1111/psj.12162

Sundaravej, T., 2013, 'Synchronous and asynchronous collaboration technology use in teamwork', Doctoral dissertation, UMI no.3670415, University of Missouri, St. Louis, viewed 20 April 2018, from https://irl.umsl.edu/dissertation/211.

Szymaniec-Mlicka, K., 2017, 'The decision-making process in public healthcare entities: Identification of the decision-making process type 1', Management 21(1), 191-204. https://doi.org/10.1515/manment-2015-0088

Varty, C.T., O'Neill, T. \& Hambley, L., 2017, Leading anywhere workers: A scientific and practical framework, IGI Global, Hershey, PA. https://doi.org/10.4018/978-1-52252328-4.ch003

Wahl, L. \& Kitchel, A., 2016, 'Internet based collaboration tools', International Journal of eCollaboration 12(1), 27-43. https://doi.org/10.4018/IJeC.2016010103

Wohlrab, P., Knauss, E., Steghöfer, J., Maro, S., Anjorin, A. \& Pelliccione, P., 2018 'Collaborative traceability management: A multiple case study from the perspectives of organization, process, and culture', Requirements Engineering 25(0), 21-45. https://doi.org/10.1007/s00766-018-0306-1

Zaraté, P., Konate, J. \& Camilleri, G., 2013, 'Collaborative decision making tools: A comparative study based on functionalities', in B. Martinovski (ed.), Proceedings on 13th International Conference Group Decision and Negotiation, University of Stockholm, Stockholm, Sweden, June 17-20, 2013, pp. 111-122. 